\title{
Branding Berbasis Digital Content Kopi Arabica Tanah Karo Dan Peningkatan Produktifitas Untuk Hilirisasi Industri Kopi Desa Lingga Kecamatan Kaban Jahe Sumatera Utara
}

\author{
Rezha Destiadi $^{1 *}$, Andi Supriadi Chan ${ }^{2}$, Orli Binta Tumanggor ${ }^{3}$ \\ 1,2,3 Teknik Komputer dan Informatika/Teknik Rekayasa Multimedia Grafis \\ ${ }^{1,2,3}$ Politeknik Negeri Medan, J1.Almamater No.1 \\ *e-mail: rezhadestiadi@polmed.ac.id \\ *Phone : 083892424972
}

Informasi Artikel

Diterima Redaksi: 10 Desember 2021

Revisi Akhir: 20 Desember 2021

Diterbitkan Online: 15 Januari 2022

Kata Kunci:

Desa lingga, karo, kopi arabica, UMKM
Abstrak

Desa lingga di kabupaten karo merupakan salah satu desa yang menjadi penghasil kopi arabica di sumatera utara. Dilihat dari letak desa lingga yang berada pada dataran tinggi maka jenis tanah disini adalah tanah lembab sehingga tanaman yang ada didominasi oleh pertanian seperti kopi, jeruk dan usaha mikro lainnya yang memiliki Potensi untuk di kembangkan.salah satunya adalah UMKM yang bergerak di pengolahan kopi. Usaha ini dikelola oleh beberapa orang dan memanfaatkan masyarakat sekitar sebagai karyawan. Beberapa permasalahan yang dihadapi oleh kelompok produktif ini seperti pemasaran yang bersifat konvensional dan manajemen pengolahan belum baik dan peralatan produksi dengan kapasitas minim. Tujuan pengabdian kepada masyarakat yang dilakukan oleh Tim Pengabdi ini untuk menyelesaiakan permasalahan yang dihadapi oleh mitra Maju dengan penerapan Iptek yang dibuat untuk menyelesaikan permasalahan dengan cara pelatihan digital content untuk pemasaran dan penjualan menggunakan foto dan video, pelatihan pengolahan proses kopi dengan standatr tinggi serta penyediaan alat giling kopi untuk menjaga mutu dan kualitas produk. Iptek yang akan di implementasikan pada mitra produktif yang berada di desa lingga adalah mesin giling kopi untuk produksi. Kemudian pelatihan digital content berbasis foto dan video, penyediaan website untuk promosi dan penjualan serta pelatihan pengolahan pasca panen kepada petani yang dimiliki agar dapat berkembang menjadi lebih baik dan mandiri. Metode yang digunakan pada kegiatan ini adalah pemberdayaan masyarakat dengan konsep berbasis masyarakat kelompok produktif (Community base Education)

dengan luas lahan 17.437,64 hektar dengan total produksi berkisar $6.788,70$ ton [1].

Pengembangan kopi di Sumatera Utara khususnya daerah Kabupaten Karo dari tahun ke tahun semakin berkembang yang ditandai dengan peningkatan jumlah areal dan produksi serta jenis kopi yang dikembangkan. Data BPS Kabupatern Karo [2] menunjukkan luas perkebunan kopi di Kec. Barusjahe $1.421 \mathrm{Ha}$ dengan total produksi 965.02 ton atau 703,88 $\mathrm{kg} / \mathrm{ha} /$ tahun. Luas rata-rata lahan kopi per kepala keluarga (KK) adalah 1, 475 ha. Luas 
lahan kopi di Kec. Tigapanah 2.044,44 ha, total produksi $1.407,52$ ton atau 1.014 $\mathrm{kg} / \mathrm{ha} /$ tahun, dan luas rata-rata lahan per KK 0,85 ha. Kec. Merek memiliki luas lahan 976 ha, total produksi 954 ton atau 1.125 $\mathrm{kg} / \mathrm{ha} /$ tahun, dengan rata-rata luas lahan per KK 2,1 ha. Peningkatan produksi tersebut dapat dicapai melalui teknik budidaya dan penggunaan faktor produksi yang semakin baik.

Meskipun produktivitas kopi di Kabupaten Karo mengalami peningkatan, namun belum sepenuhnya diimbangi dengan permintaan pasar yang tinggi terhadap kopi, sehingga masih dibutuhkan peningkatan pemasaran dan penjualan di daerah tersebut. Berbicara tentang kopi khas Tanah Karo, kopi ini sudah terkenal sejak lama oleh masyarakat Indonesia khususnya masyarakat Tanah Karo. Dan pada zaman penjajahan Belanda kopi ini sudah dibawa ke Eropa untuk diperdagangkan, dan persebaran kopi ini semakin meluas. Kopi ini memang mempunya rasa yang unik dibandingkan dengan kopi pada umumnya, sebagian kopi yang di budidayakan di Tanah Karo merupakan kopi Arabika yang memiliki cita rasa yang mendunia.

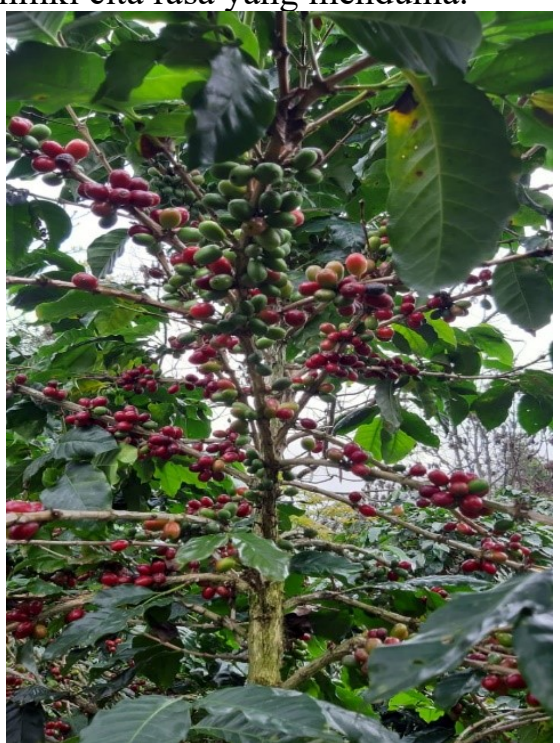

Gambar 1.1. Kebun kopi arabica Kab. Karo

Pandemi Covid-19 yang terjadi secara global tentu saja berdampak terhadap berbagai sektor terutama di sektor ekonomi.Dampak perekonomian ini tidak hanya di rasakan secara domestik, namun juga terjadi secara global. International Monetary Fund (IMF) yang memproyeksikan ekonomi global akan tumbuh minus di angka 3\% [3]. Di Indonesia, Hal ini tentunya juga memiliki dampak yang cukup signifikan terhadap pariwisata, sektor perdagangan, industri termasuk Pelaku Usaha Mikro, Kecil dan Menengah (UMKM)[4].

Berdasarkan riset lapangan dan diskusi dengan kelompok petani kopi dan prossessor kopi milik pak weldi, kesulitan dalam pemasaran dan penjualan hasil produksi kopi arabica yang berasal dari tanah karo. Dan belum adanya strategi pemasaran yang baik untuk menarik minat pembeli terutama sejak pandemic COVID 19 masuk Indonesia sejak 2020. Padahal pak weldi berserta kelompoknya adalah salah satu pelopor dalam hilirisasi industri kopi di tanah karo sejak tahun 2016.

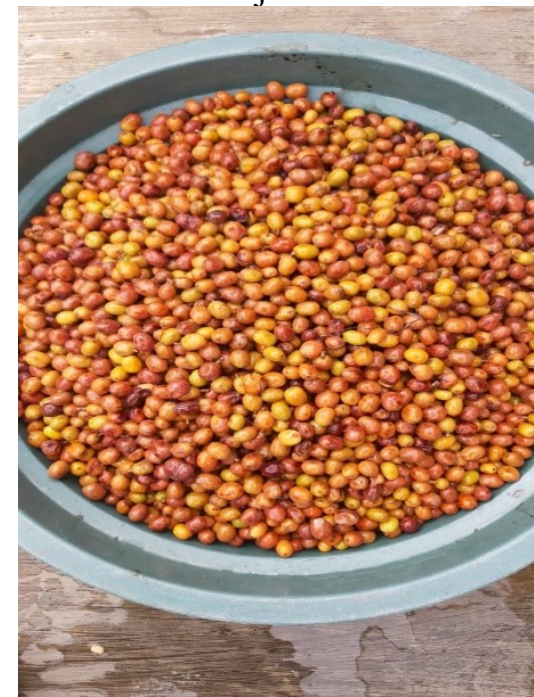

Gambar 1.2 Proses Pengolahan Kopi dari ceri hingga jadi beras kopi

Usaha produksi kopi dari buah ceri hingga menjadi green bean ini sudah mengerjakan 10 karyawan tetap dan karyawan lepas yang berasal dari masyarakat sekitar. Hal ini dikarenakan pengelola usaha ini berencana untuk memberdayakan masyarakat sekitar untuk menambah skill dan kemampuan agar dapat secara mandiri membuat usaha yang serupa. Tetapi kekuatan dari sebuah brand yang dimiliki serta strategi pemasaran dalam penjualan hasil dari panen kopi belumlah maksimal.

Berdasarkan interview dengan pak weldi yang juga seorang petani dan prossesor kopi arabica, media pemasaran saat ini masih sebatas menggunakan social media dan promosi langsung ke lapangan. 
Dan dari sisi pengambilan gambar untuk promosi pun masih seadanya tanpa kreatifitas yang cukup, padahal sejak masa pandemic pelaku UMKM diharapkan dapat menjadi lebih kreatif dan memanfaatkan teknologi yang ada dengan baik dan bijak seperti penggunaan digital content.

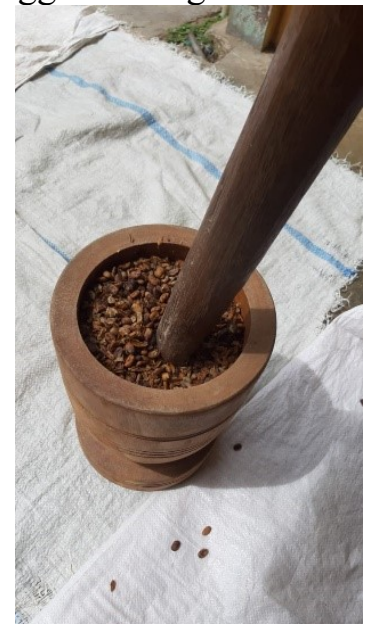

Gambar 1.3 Proses penggilingan kopi secara manual

Dan dari teknologi pengolahan biji kopi menjadi bubuk kopi arabica masih menggunakan mesin seadanya, Padahal menurut dari beberapa konsumen yang ditemui secara langsung. Kualitas hasil produksi kelompok ini sangat bagus dan baik serta disukai oleh pelanggan.dengan menggunakan peralatan giling kopi lama yang masih kecil. Kapasitas produksi kopi mereka menjadi sangat terbatas. Sementara permintaan tcukup tinggi sehingga kinerja mesin menjadi tidak maksimal. Karna untuk menggiling $10 \mathrm{Kg}$ gabah kopi membutuhkan waktu hingga 30 menit dikarenakan kapasitas mesin yang kecil dan tidak bisa digunakan terus menerus dalam jangka waktu yang lama karena akan menyebabkan mesin cepat panas dan mengalami kerusakan. Makanya terkadang digunakan alat penggiling manual dan hal tersebut membuat kualitas menjadi menurun.

\section{METODE}

Adapun pihak-pihak yang terlibat dalam kegiatan ini sebagai berikut:

1. Tim Pelaksana kegiatan program pengabdian kepada masyarakat pada desa beringin tim memiliki keahlian yang berbeda-beda.

2. Mahasiswa jurusan Teknik computer dan informatika yang akan membantu merancang, membangun website dan pelatihan digital content sesuai kebutuhan petani kopi di kabupaten karo.

3. Kelompok petani kopi di kecamatan kaban jahe baik yang sudah memberikan izin dan mendukung kegiatan untuk pengabdian.

\subsection{Metode dan Tahapan Pengabdian}

Tahapan-tahapan pelaksanaan kegiatan sebagai berikut:

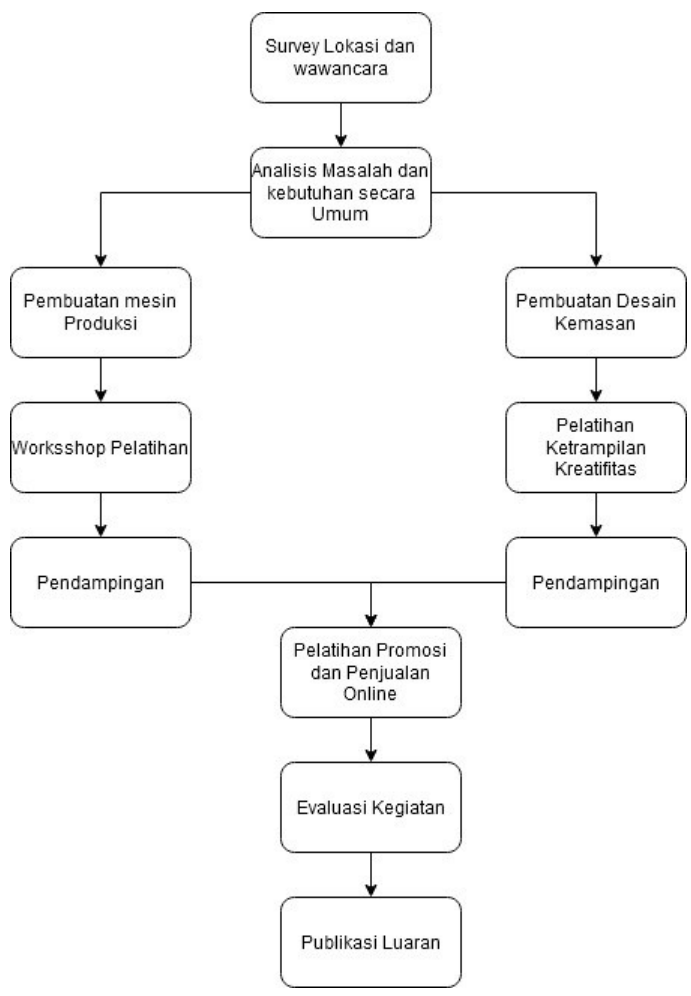

Gambar 2.1 Tahapan Pelaksanan Kegiatan

\section{HASIL DAN PEMBAHASAN}

\subsection{Persiapan Kegiatan}

Pada tahap awal pelaksanaan program dilaksanakan kegiatan berupa pemberian alat dan kegiatan pelatihan, persiapan peralatan, peserta kegiatan pelatihan dilaksanakan bersama tim pengusul didasari oleh analisis situasi yang dibuat berdasarkan permasalahan yang dihadapi oleh mitra. kegiatan ini dilaksanakan pada Bulan November 2021 yang juga melibatkan peran serta aktif peserta program pengabdian kepada masyarakat untuk membuat skala prioritas program yang dilaksanakan. Perencanaan ini berjalan dengan sangat baik berkat peranan 
aktif tim pelaksana dan peserta yang menjadi mitra program. Kegiatan pemberian alat berupa Huller Kopi untuk meningkatkan kapasitas produksi penggilingan kopi arabica pada desa Lingga.

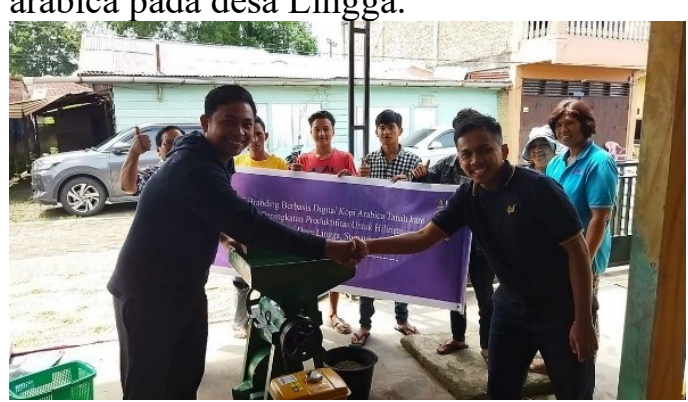

Gambar 3.1 Kegiatan pemberian alat berupa Huller Kopi

\subsection{Pelaksanaan Kegiatan}

Setelah penyerahan semua peralatan. Maka tahapan selanjutnya pelaksanaan kegiatan. Kegiatan dilaksanakan kedalam 2 tahap:

1. Pelatihan penggunaan Alat

Sebelum peserta melaksanakan kegiatan peserta dipandu cara penggunaan untuk masing-masing alat yang telah diberikan.Uraian kegiatan berupa pemahaman pentingnya keamanan dan teknis dalam penggunaan alat untuk produksi, hal ini dikarenakan untuk keamanan saat bekerja agar tidak menimbulkan resiko cedera saat penggunaan alat yang telah diberikan.

Setelah peserta memahami mengenai penggunaan alat tersebut kemudian Peserta mulai melakukan ujicoba terhadap masing-masing alat.

1. Pemanfaatan e-commerce sebagai media promosi

Peserta diajarkan mengenai teknik penggunaan aplikasi e-commerce, Mulai dari cara peserta mendaftarkan produk, mendaftarkan user, proses posting dan lain sebagainya.

\subsection{Evaluasi Kegiatan}

Evaluasi kegiatan diberikan melalui uji penggunaan alat terhadap seluruh peserta. Berikut kesimpulan yang didapat dari hasil evaluasi peserta :

a. Peserta memahami dengan baik bagaimana cara penggunaan alat produksi yang sudah diberikan.

b. Peserta juga sudah bisa menginputkan beberapa gambar dalam aplikasi seperti (Input data barang, data deskripsi produk, , dan penulisan artikel e-commerce)

c. Peserta sangat antusias untuk menerapkannya di e-commerce masing-masing..

d. Setelah diadakan pelatihan pemahaman peserta semakin meningkat akan pentingnya penggunaan aplikasi e-commerce untuk pemasaran dan penggunaan alat produksi yang telah diberikan.

\begin{tabular}{|c|c|}
\hline Mitra Kegiatan & $\begin{array}{l}\text { Kelompok Petani } \\
\text { desa lingga Karo }\end{array}$ \\
\hline Jumlah Mitra & 10 orang \\
\hline Pendidikan Mitra & $\begin{array}{l}\text { - S3 - orang } \\
\text { - S2 -. orang } \\
\text { - S1 -1 orang } \\
\text { - Diploma -orang } \\
\text { - SMA -1 orang } \\
\text { - SMP -2 orang } \\
\text { - SD - 6 orang } \\
\text { - Tidak } \\
\text { Berpendidikan - } \\
\text { orang }\end{array}$ \\
\hline $\begin{array}{l}\text { Permasalahan } \\
\text { Mitra: Teknologi, } \\
\text { Manajemen, } \\
\text { Sosial-Ekonomi, } \\
\text { Hukum, } \\
\text { Keamanan, } \\
\text { Lainnya }\end{array}$ & $\begin{array}{l}\text { Pemasaran produk } \\
\text { yang masih bersifat } \\
\text { konvensional dan } \\
\text { tradisional.Keterba } \\
\text { tasan alat kerja } \\
\text { dalam proses kopi } \\
\text { arabica pada usaha } \\
\text { di desa lingga. } \\
\text { Masih minimnya } \\
\text { pengetahuan dan } \\
\text { keahlian yang } \\
\text { dimiliki oleh petani } \\
\text { dalam kegiatan } \\
\text { pengolahan kopi } \\
\text { arabica dan tidak } \\
\text { adanya keahlian } \\
\text { dalam penggunaan } \\
\text { alat kerja. Belum } \\
\text { adanya merek } \\
\text { dagang produk } \\
\text { yang dimiliki oleh } \\
\text { usaha kopi arabica } \\
\text { untuk penjualan } \\
\text { sehingga kemasan } \\
\text { dan nilai jual yang } \\
\text { kurang menarik. }\end{array}$ \\
\hline $\begin{array}{l}\text { Status Sosial Mitr } \\
\text { Pengusaha Mikro }\end{array}$ & $\begin{array}{l}\text { Status sosial Mitra } \\
\text { adalah pengusaha }\end{array}$ \\
\hline
\end{tabular}




\begin{tabular}{|c|c|}
\hline $\begin{array}{l}\text { Anggota Koperasi, } \\
\text { Kelompok } \\
\text { Tani/Nelayan, } \\
\text { PKK/Karang } \\
\text { Taruna, Lainnya } \\
\text { (Tuliskan yang } \\
\text { sesuai) }\end{array}$ & $\begin{array}{l}\text { mikro untuk usaha } \\
\text { rumah tangga } \\
\text { yang belum } \\
\text { memperoleh izin } \\
\text { usaha. }\end{array}$ \\
\hline LOKASI & $\begin{array}{l}\text { Desa lingga, } \\
\text { Kecamatan } \\
\text { kabanjahe } \\
\text { Kabupaten Karo }\end{array}$ \\
\hline $\begin{array}{l}\text { Jarak PT ke Lokasi } \\
\text { Mitra }\end{array}$ & $75 \mathrm{KM}$ \\
\hline $\begin{array}{l}\text { Sarana } \\
\text { Transportasi: } \\
\text { Angkutan Umum, } \\
\text { Motor, Jalan Kaki } \\
\text { (Tuliskan yang } \\
\text { sesuai) }\end{array}$ & $\begin{array}{l}\text { Sarana transfortasi } \\
\text { menuju ke mitra } \\
\text { menggunakan } \\
\text { mobil }\end{array}$ \\
\hline $\begin{array}{l}\text { Sarana } \\
\text { Komunikasi: } \\
\text { telepon, internet, } \\
\text { surat, fax, tidak ada } \\
\text { sarana komunikasi } \\
\text { (tuliskan yang } \\
\text { sesuai) }\end{array}$ & $\begin{array}{l}\text { Sarana Komunikasi } \\
\text { kepada mitra } \\
\text { menggunakan } \\
\text { telepon. }\end{array}$ \\
\hline IDENTITAS & \\
\hline Tim PKM & $\begin{array}{l}\text { Rezha Destiadi } \\
\text { Andi Supriadi } \\
\text { Chan } \\
\text { Orli Binta } \\
\text { Tumanggor } \\
\end{array}$ \\
\hline Jumlah Dosen & 3 orang \\
\hline Jumlah Mahasisw & 2 or \\
\hline $\begin{array}{l}\text { Gelar Akademik } \\
\text { Tim }\end{array}$ & $\begin{array}{l}\text { S-3 - 0 orang } \\
\text { S2 sebanyak } 3 \\
\text { orang } \\
\text { S1 - orang }\end{array}$ \\
\hline Jenis Kelamin & $\begin{array}{l}\begin{array}{l}\text { Laki-laki } 2- \\
\text { orang } \\
\text { Perempuan } 1 \text { orang }\end{array} \\
\end{array}$ \\
\hline \multicolumn{2}{|l|}{$\begin{array}{l}\text { AKTIVITAS } \\
\text { PKM }\end{array}$} \\
\hline $\begin{array}{l}\text { Metode } \\
\text { Pelaksanaan } \\
\text { Kegiatan: } \\
\text { Penyuluhan/Penyad } \\
\text { aran, } \\
\text { Pendampingan, } \\
\text { Pendidikan, } \\
\text { Demplot, Rancang } \\
\text { Bangun, Pelatihan, } \\
\text { Manajemen Usaha, } \\
\text { Pelatihan Produksi, }\end{array}$ & $\begin{array}{l}\text { Pelaksanaan } \\
\text { kegiatan dilakukan } \\
\text { melalui kegiatan } \\
\text { pelatihan } \\
\text { penggunaan alat } \\
\text { produksi, } \\
\text { Pendampingan dan } \\
\text { pelatihan kepada } \\
\text { petani Desa } \\
\text { Lingga, dan } \\
\text { Pemberian }\end{array}$ \\
\hline
\end{tabular}

\begin{tabular}{|c|c|}
\hline $\begin{array}{l}\text { Pelatihan } \\
\text { Administrasi, } \\
\text { Pengobatan, } \\
\text { Lainnya (tuliskan } \\
\text { yang sesuai) }\end{array}$ & $\begin{array}{l}\text { peralatan produksi } \\
\text { berupa mesin } \\
\text { huller kopi untuk } \\
\text { menambah } \\
\text { peralatan Produksi } \\
\text { Petani untuk } \\
\text { membantu } \\
\text { peningkatan } \\
\text { produksi usaha } \\
\text { Kopi arabica }\end{array}$ \\
\hline $\begin{array}{l}\text { Waktu Efektif } \\
\text { Pelaksanaan } \\
\text { Kegiatan }\end{array}$ & 45 Hari \\
\hline $\begin{array}{l}\text { EVALUASI } \\
\text { KEGIATAN }\end{array}$ & \\
\hline Keberhasilan & Berhasil \\
\hline $\begin{array}{l}\text { INDIKATOR } \\
\text { KEBERHASILA } \\
\mathbf{N}\end{array}$ & \\
\hline $\begin{array}{l}\text { Keberlanjutan } \\
\text { Kegiatan di Mitra }\end{array}$ & Berlanjut \\
\hline Kapasitas Produksi & $\begin{array}{l}\text { Sebelum PKM } \\
\text { jumlah karyawan } \\
\text { yang dapat } \\
\text { diberdayakan untuk } \\
\text { membantu usaha } \\
\text { petani lingga hanya } \\
2 \text { orang, kini } \\
\text { setelah PkM } \\
\text { jumlah pemuda } \\
\text { yang dapat } \\
\text { diberdayakan untuk } \\
\text { membantu } \\
\text { produksi usaha } \\
\text { kopi arabica } \\
\text { menjadi } 8 \text { orang. }\end{array}$ \\
\hline Omzet per bulan & $\begin{array}{l}\text { Kurang lebih } 3 \text { Juta } \\
\text { Rupiah }\end{array}$ \\
\hline $\begin{array}{l}\text { Persoalan } \\
\text { Permasalahan } \\
\text { Mitra }\end{array}$ & $\begin{array}{l}\text { Terselesaikan/ } \\
\text { sebagian }\end{array}$ \\
\hline \multicolumn{2}{|l|}{$\begin{array}{l}\text { KONTRIBUSI } \\
\text { MITRA }\end{array}$} \\
\hline $\begin{array}{l}\text { Peran Serta Mitra } \\
\text { Dalam Kegiatan }\end{array}$ & Aktif \\
\hline $\begin{array}{l}\text { Kontribusi } \\
\text { Pendanaan }\end{array}$ & $\begin{array}{l}\text { Menyediakan } \\
\text { (Menyediakan } \\
\text { Tempat) }\end{array}$ \\
\hline Peranan Mitra & $\begin{array}{l}\text { - Objek Kegiatan } \\
\text { - Subjek Kegiatan }\end{array}$ \\
\hline $\begin{array}{l}\text { KEBERLANJUT } \\
\text { AN }\end{array}$ & \\
\hline
\end{tabular}




\begin{tabular}{|c|c|}
\hline $\begin{array}{l}\text { Alasan } \\
\text { Keberlanjutan } \\
\text { Kegiatan Mitra }\end{array}$ & $\begin{array}{l}\text { Keputusan } \\
\text { bersama }\end{array}$ \\
\hline $\begin{array}{l}\text { USUL } \\
\text { PENYEMPURNA } \\
\text { AN PKM } \\
\end{array}$ & \\
\hline $\begin{array}{l}\text { Model Usulan } \\
\text { Kegiatan }\end{array}$ & $\begin{array}{l}\text { Pelaksanaan PKM } \\
\text { sebaiknya } \\
\text { dilaksanakan } \\
\text { dengan melibatkan } \\
\text { pihak Desa }\end{array}$ \\
\hline $\begin{array}{l}\text { Potret } \\
\text { Permasalahan lain } \\
\text { yang terekam }\end{array}$ & $\begin{array}{l}\text { Mitra masih } \\
\text { membutuhkan } \\
\text { pendampingan } \\
\text { untuk membuat } \\
\text { Kataloq Produksi } \\
\text { Kopi arabica karo } \\
\text { dan pendampingan } \\
\text { untuk kegiatan } \\
\text { pemasaran produk }\end{array}$ \\
\hline \multicolumn{2}{|c|}{\begin{tabular}{l|l} 
LUARAN & \\
PROGRAM PKM & \\
\end{tabular}} \\
\hline Jasa & $\begin{array}{l}\text { Ada, berupa } \\
\text { Pelatihan }\end{array}$ \\
\hline Metode atau Sistem & Tidak ada \\
\hline Produk/Barang & Tidak ada \\
\hline Paten & Tidak ada \\
\hline $\begin{array}{l}\text { Publikasi } \\
\text { (Artikel/Proceeding } \\
\text { ) }\end{array}$ & Draft \\
\hline $\begin{array}{l}\text { Publikasi Media } \\
\text { Masa }\end{array}$ & $\begin{array}{l}\text { - Terpublikasi di } \\
\text { OkeMedan.com } \\
\text { - Video yang } \\
\text { dapat diakses } \\
\text { online } \\
\text { (Youtube) }\end{array}$ \\
\hline
\end{tabular}

\subsection{Evaluasi Kegiatan}

Evaluasi program dilakukan untuk mengetahui hasil dan progressdari pelaksanaan program yang telah direncanakan. Evaluasi ini dilakukan dengan caramembandingkan kondisi kedua mitra sebelum program dilaksanakan dan kondisi mitra setelah program dilaksanakan. Secara rinci, evaluasi program dapat dilihat berdasarkan tabel berikut :

\begin{tabular}{|l|l|l|l|}
\hline $\begin{array}{c}\text { Progra } \\
\text { m }\end{array}$ & $\begin{array}{l}\text { Indikat } \\
\text { or }\end{array}$ & Kriteria & $\begin{array}{l}\text { Instru } \\
\text { men }\end{array}$ \\
\hline Sosialisa & Pemaha & Peningk & Observ \\
si & man & atan & asi \\
mekanis & mitra & pemaha & Wawan \\
me & mengen & man & car \\
strategi & ai & mekanis & \\
\hline
\end{tabular}

\begin{tabular}{|c|c|c|c|}
\hline $\begin{array}{l}\text { pemasar } \\
\text { an guna } \\
\text { peningka } \\
\text { tan } \\
\text { penjuala } \\
\text { n barang } \\
\text { dan jasa } \\
\text { menggu } \\
\text { nakan } \\
\text { Teknolo } \\
\text { gi }\end{array}$ & $\begin{array}{l}\text { mekani } \\
\text { sme } \\
\text { strategi } \\
\text { pemasa } \\
\text { ran } \\
\text { dalam } \\
\text { kegiata } \\
\text { n usaha } \\
\text { dengan } \\
\text { pemanf } \\
\text { aatan } \\
\text { teknolo } \\
\text { gi }\end{array}$ & $\begin{array}{l}\text { me } \\
\text { strategi } \\
\text { pemasar } \\
\text { an } \\
\text { Penerap } \\
\text { an } \\
\text { strategi } \\
\text { pemasar } \\
\text { an dalam } \\
\text { kegiatan } \\
\text { usaha } \\
\text { menggu } \\
\text { nakan } \\
\text { teknolog } \\
\text { i }\end{array}$ & \\
\hline $\begin{array}{l}\text { Pelatiha } \\
\mathrm{n} \\
\text { penggun } \\
\text { aan alat } \\
\text { dan } \\
\text { keselata } \\
\text { matan } \\
\text { untuk } \\
\text { scale up } \\
\text { produksi }\end{array}$ & $\begin{array}{l}\text { Pemaha } \\
\text { man } \\
\text { mitra } \\
\text { mengen } \\
\text { ai alat } \\
\text { produks } \\
\text { i dan } \\
\text { keselam } \\
\text { atan }\end{array}$ & $\begin{array}{l}\text { Peningk } \\
\text { atan } \\
\text { Pemaha } \\
\text { man } \\
\text { mitra } \\
\text { mengena } \\
\text { i alat } \\
\text { produksi } \\
\text { dan } \\
\text { keselam } \\
\text { atan }\end{array}$ & $\begin{array}{l}\text { Observ } \\
\text { asi } \\
\text { Wawan } \\
\text { cara } \\
\text { Works } \\
\text { hop }\end{array}$ \\
\hline $\begin{array}{l}\text { Sosialisa } \\
\text { si } \\
\text { Pengenal } \\
\text { an } \\
\text { Merek } \\
\text { dan } \\
\text { Legalitas } \\
\text { Merek }\end{array}$ & $\begin{array}{l}\text { Pemaha } \\
\text { man } \\
\text { mitra } \\
\text { mengen } \\
\text { ai } \\
\text { merek } \\
\text { dagang/ } \\
\text { jasa } \\
\text { dalam } \\
\text { kegitan }\end{array}$ & $\begin{array}{l}\text { Peningk } \\
\text { atan } \\
\text { pemaha } \\
\text { man } \\
\text { mengena } \\
\text { i merek, } \\
\text { Peningk } \\
\text { atan } \\
\text { pemaha } \\
\text { man } \\
\text { legalitas } \\
\text { merek, } \\
\text { Pendafta } \\
\text { ran } \\
\text { merek }\end{array}$ & $\begin{array}{l}\text { Observ } \\
\text { asi } \\
\text { Wawan } \\
\text { car }\end{array}$ \\
\hline
\end{tabular}

Setelah keseluruhan program selesai dilaksanakan, maka penting untuk direncanakan keberlanjutan program tersebut. Adapun keberlanjutan program di lapangan setelah kegiatan PKM selesai dilaksanakan, meliputi :

1. Monitoring pembuatan merek dan pendaftaran merek dagang/ jasa

2. Monitoring penerapan strategi pemasaran dalam kegiatan usaha dengan pemanfaatan teknologi 
3. Sosialisasi pemasaran online dalam kegiatan bisnis beserta aspek hukumnya bagi mitra.

4. Pelatihan keberlanjutan dalam kegiatan produksi

\section{KESIMPULAN}

Berdasarkan hasil pelaksanaan kegiatan pengabdian kepada masyarakat, diperoleh kesimpulan dan saran sebagai berikut:

1. Kendala keterbatasan alat dapat diatasi dengan penerimaan alat produksi berupa mesin huller kopi arabica yang diberikan Tim PKM.

2. Usaha kopi arabica di Desa lingga akb. karo mulai memahami memiliki strategi untuk mengembangkan usaha, walaupun masih membutuhkan pendampingan promosi melalui E-commerce.

3. Kopi Arabica desa Lingga sudah memahami cara penggunaan alat produksi dengan baik dan benar sehingga keamanan dalam proses produksi dapat dicapai.

4. Usaha kopi arabica pada desa lingga kini memperoleh kapasitas produksi yang lebih besar ikut memproduksi kopi arabica karena telah memperoleh bantuan alat dan pelatihan sehingga dapat menambah kapasitas produksi.

\section{SARAN}

Memperhatikan sangat bermanfaatnya kegiatan keterampilan bagi perempuan usia produktif bagi yang berpendidikan rendah, maka sangat dibutuhkan kegiatan keterampilan ini dapat dilanjutkan untuk diberikan pada jumlah masyarakat yang lebih banyak di desa yang berbeda sehingga akhirnya anggota petani kopi arabica desa lingga usia produktif ini menjadi berdaya usaha dan dapat membantu penghidupan keluarga mereka

\section{UCAPAN TERIMA KASIH}

Pengabdian pada masyarakat ini dapat terlaksana dengan bantuan berbagai pihak. Untuk itu, pada kesempatan ini diucapkan terima kasih yang sebesar- besarnya kepada Bapak/Ibu Tim P3M Politeknik Negeri Medan, terima kasih telah membantu dan menjadi tim kerjasama yang baik untuk mendukung kegiatan penelitian dan pengabdian masyarakat di lingkungan Politeknik Negeri Medan.

\section{REFERENSI}

[1] D. Dahang et al., "PENGARUH TEKNIK BUDIDAYA TERHADAP PRODUKSI KOPI," vol. 4, no. 2, pp. 47-62, 2020.

[2] E. Frida, T. Sembiring, F. R. A. Bukit, and ..., "Implementation Of Wet Coffee Peeling Machine In Barus Julu Village, Kecamatan Barus Jahe, Karo District," Abdimas Talent. ..., vol. 5, no. 2, pp. 302 308, 2020, [Online]. Available: https://talenta.usu.ac.id/abdimas/arti cle/view/4884.

[3] W. laura Hardilawati, "Strategi Bertahan UMKM di Tengah Pandemi Covid-19," J. Akunt. dan Ekon., vol. 10, no. 1, pp. 89-98, 2020, doi: 10.37859/jae.v10i1.1934.

[4] Covid19.go.id, "No Title," www.covid19.go.id, 2020. . 